\title{
Workshop on Spinal Cord Injuries (SCI) Management: the Chiang Mai Experience
}

\author{
A Kovindha*,1 and P Dollfus ${ }^{2}$ \\ ${ }^{1}$ Department of Rehabilitation Medicine, Faculty of Medicine, Chiang Mai University, Thailand. ${ }^{2} 72$ rue des carrieres, \\ Mulhouse, France.
}

\begin{abstract}
Objectives: To give an opportunity to health workers in South Asia (SEA) to improve their knowledge in the comprehensive management of SCI.

Setting: Chiang Mai, Thailand; 5-7 November 1997.

Participants: Sixteen faculty members (from Europe, Australia and Thailand) and 160 participants (94 Thais, 66 from SEA, China, India and Bangledesh).

Methods: Two days of lectures and 1 day of workshops and discussion. Evaluation was performed by questionnaires. Suggestions and comments are reported.

Results: Ninety-two per cent of participants said the workshop was really useful. Eightyeight per cent were very satisfied with the quality of the programmes and $92 \%$ with the workshops and discussion on the last day.

Conclusions: A follow-up study should be conducted by the Educational Committee of IMSOP. This will help to plan more efficacious training programmes for the future.
\end{abstract}

Keywords: spinal cord injury; education workshops; developing countries

\section{Introduction}

Sir Ludwig Guttmann (1973) stated that in the comprehensive management of SCI it is crucial to use the appropriate rehabilitation programmes throughout the acute care and rehabilitation. ${ }^{1,2}$ All victims need a life-long follow-up. ${ }^{3}$ These requirements rarely exist in developing countries where there is a lack of adequate primary medical management, limited equipment and financial resources. Often, there is a lack of experience and motivation of medical and allied professions. Thus the first training programme in SCI, organised by Air Marshall Chahal and IMSOP, was held in New Dehli, India, in 1995, in association with the Government of India and WHO. One of its successes was the recognition of comprehensive management by teamwork. The second workshop on SCI management was held in Chiang Mai, Thailand, under the banners of the Faculty of Medicine, Chiang Mai University, IMSOP, and the support of the Swiss Paraplegic Foundation (SPF). This workshop was organised for the medical and the allied professions in Southeast Asia (SEA) to learn and to share their experience with experts within the various fields of SCI management.

\section{Methods}

A 3 day workshop (5-7 November 1997) consisted of 2 days of lectures and 1 day with six different workshops:

*Correspondence, A Kovindha, Department of Rehabilitation Medicine, Faculty of Medicine, Chiang Mai University, Chiang Mai 50200, Thailand neuropathic bladder, pressure sores, sexual dysfunction, physiotherapy (PT), occupational therapy (OT) and nursing care. Specialists from fields such as orthopaedics, rehabilitation, neurology, urology, plastic surgery, psychology, nursing, PT and OT, gave their services free. The cost of registration was 1500 baht (\$US 40) per person. The SPF allocated funds to help those with financial difficulties. Local medical and pharmaceutical companies provided additional financial and technical support. Information about the workshop was given about 8-12 months in advance through mailings, posters, announcements in Spinal Cord and by Internet. Participants pre-registered and chose two specific workshops for the last day. Almost all participants were under the age of 45 and had some experience with SCI patients. A month before the opening day, the organising staff met to discuss their respective roles in the planning of the workshop, and to prepare handouts and questionnaires. The participants were asked to complete evaluation questionnaires. Thanks to the generosity of SPF the manual 'Disabled Children Village, ${ }^{4}$ was distributed to representatives of each hospital. Finally, the organiser prepared a report on the workshop and sent it to the responsible authorities and supporters.

\section{Results}

There were 16 Faculty members from seven countries in Europe, Australia, and Thailand, and 160 participants from 12 countries (see Table 1). Forty-six of 


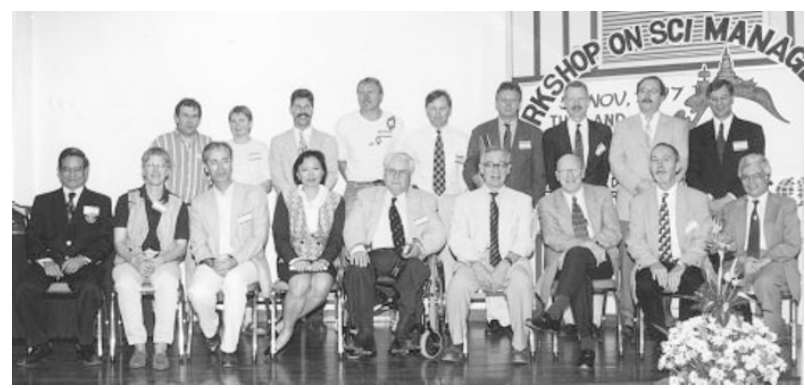

Figure 1 The Faculty members of the workshop

them, from developing countries in SEA including China, India and Bangladesh, were supported financially by the SPF. The financial support came to approximately \$US 8840 (one US dollar was approximately, in November 1997, equal to 40 Thai bahts). The balance came from registration fees and local supporting companies. Nearly $80 \%$ of the total expenses (\$US 7300) was spent on organising the workshop and the rest on the Faculty's expenses, excluding the Faculty's travel expenses. Some Faculty were helped by SPF and IMSOP.

Evaluation questionnaires were distributed to the participants at the end of the workshop. They were only filled in by 74 participants $(46 \%)$ : 38 were doctors, 8 nurses, 9 PTs, 2 OTs, (the rest did not mention their profession). According to the questionnaires, $84 \%$ were very satisfied with the efficiency of the workshop staff, $82 \%$ with the conference facilities, $88 \%$ with the scientific quality of the programme and $92 \%$ with the workshop and discussion on the last day. Eighty per cent thought that the workshop was just right for their professions, $10 \%$ that the standard was too low; and $10 \%$ that the level was too high. Fifty-four per cent had no difficulty in understanding while $34 \%$ thought they had some problems. Thirteen per cent complained that the speakers spoke too quickly. Fifty per cent said that there was not enough time for discussion.

Participants attended as a team (doctor, nurse, PT and OT from the same hospital) and $78 \%$ thought that others in their team were satisfied with the overall understanding of the teaching. Forty-nine per cent agreed that the sessions should be divided. More time (up to 4-5 days) should be alloted for such an important multidisciplinary workshop. Practical and demonstration session should be increased. Overall, $92 \%$ thought that the workshop was useful to them. Fifty-eight per cent thought that they would be able to apply what they had learned in their own countries, and $78 \%$ that they could easily teach what they had learned to others. Regarding future cooperation in multidisciplinary research projects on education concerning SCI, $73 \%$ agreed to do so, and $61 \%$ also agreed to fill another questionnaire on this subject.
Table 1 Participants attending the workshop

\begin{tabular}{|c|c|c|c|c|c|c|}
\hline \multirow{2}{*}{ Countries } & \multicolumn{5}{|c|}{ Number of participants } & \multirow[b]{2}{*}{ Total } \\
\hline & Doctor & Nurse & $P T$ & $O T$ & Others & \\
\hline 1 Brunei & - & - & 1 & - & - & 1 \\
\hline 2 Bangladesh & 1 & 2 & - & - & - & 3 \\
\hline 3 Cambodia & 1 & 1 & - & - & - & 2 \\
\hline 4 China & 3 & - & - & - & - & 3 \\
\hline 5 India & 2 & 1 & 1 & - & - & 4 \\
\hline 6 Indonesia & 10 & 2 & 2 & - & - & 14 \\
\hline 7 Lao & 1 & 1 & 1 & - & - & 3 \\
\hline 8 Malaysia & 5 & 8 & 5 & 1 & 1 & 20 \\
\hline 9 Philippines & 1 & 1 & 2 & 1 & - & 5 \\
\hline 10 Singapore & - & 4 & 3 & 1 & - & 8 \\
\hline 11 Thailand & 34 & 27 & 20 & 10 & 3 & 94 \\
\hline 12 Vietnam & 1 & 2 & - & - & - & 3 \\
\hline Total & 59 & 49 & 35 & 13 & 4 & 160 \\
\hline
\end{tabular}

Participants' suggestions and comments for a future workshop were as follows:

- Further cooperation with experts within the region (SEA).

- Simpler and more appropriate management methods, specific case presentations and discussions, applicable to developing countries.

- Topics and discussions concerning the specific problems faced by SCI units in developing countries.

- Smaller discussion groups concerned with problems related to rehabilitation and follow-up.

- Annual regional workshops with less participants.

\section{Discussion}

This workshop proved to be useful for the participants form the SEA countries. It gave educational opportunities not only to doctors but also to the allied medical professions thus enabling them to work more effectively as a team. However, to overcome the problems of different multidisciplinary backgrounds and interests, the teaching sessions were divided into general basic themes for all concerned, followed by workshops on separate chosen topics. One tried to achieve this in the workshop's programmed but it should have been in a different ratio. Perhaps less time should have been devoted to the general topics and more time for small groups of discussion and practice. This would have required more time, in days, in order to have more 'hands-on' practical experience.

English appears to be the most suitable language to be used in SEA countries. In addition, speakers must be well chosen for their teaching ability and experience with such an audience. They should speak slowly and their English should be easy to understand. Their audio-visual aids must be simple and appropriate. Having multidisciplinary teams attending did help in 
comprehension as did the handouts and basic and clear presentations. Feedback from the participants was valuable but, unfortunately only $46 \%$ returned the questionnaires. Thsi could be improved by requiring the questionnaire to be submitted before the last session. Participants' comments and suggestions should be taken into consideration for the future workshops.

Regarding the management of the workshop, the organiser was well prepared in advance and was given international and national support (IMSOP, SPF, Chiang Mai University). There were more participants than expected. Most of the participants were satisfied with the overall structure of the programme. Nearly all had participated full-time. However, too many participants can be a weak point for effective teaching and learning. Therefore, the number of participants should be limited in future workshops and applications carefully selected. Moreover, an essential aim of this type of workshop is to create active involvement by each participant, and to work and to learn from practical experience. Such aims should be clearly and fully expressed. Arrangements of a workshop should be carried out systematically but may be flexible. ${ }^{5}$

\section{Conclusions}

It is one of the tasks for the Educational Committee of IMSOP, and the national or regional organisers, to create and encourage, even in difficult circumstance, a continuing educational programme and its follow-up. This aim should continue in different regions where resources though limited, are still available and where the cost for this type of organisation is economically acceptable. Finally, one has to ensure that it should benefit all spinal cord sufferers, whether post traumatic or not. ${ }^{6}$

\section{References}

1 Guttmann L. Spinal cord injuries: comprehensive management and research. Oxford: Blackwell Scientific Publications, 1973.

2 Frankel HL. Natural history and rehabilitation in spinal cord damage. In Illis LS (ed). Neurological Rehabilitation. 2nd edn. Oxford: Blackwell Scientific Publications, 1994; pp 221-238.

3 Bedbrook GM. Lifetime care of the paraplegic patient. Edinburgh: Churchill Livingstone, 1985; pp 1-6.

4 Werner D. Disable Village Children. 3rd edn. Hesperian Foundation: Palo Alto, 1996.

5 Abbatt FR, Mejia A. Continuing the education of health workers: a workshop manual. WHO: Geneva 1988

6 Harris P. Envoi. Spinal Cord 1997; 35: $793-745$. 